\title{
Catastrophic health spending in Mexico and its determinants, 2002-2014
}

\author{
Román Rodríguez-Aguilar ${ }^{1}$ and Gustavo Rivera-Peña ${ }^{2}$

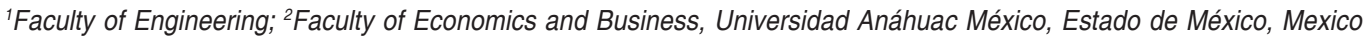

\begin{abstract}
Objective: To assess the financial protection of public health insurance by analyzing the percentage of households with catastrophic health expenditure (HCHE) in Mexico and its relationship with poverty status, size of locality, federal entity, insurance status and items of health spending. Method: Mexican National Survey of Income and Expenditures 2002-2014 was used to estimate the percentage of HCHE. Through a probit model, factors associated with the occurrence of catastrophic spending are identified. Analysis was performed using Stata-SE 12. Results: In 2014 there were $2.08 \%$ of HCHE (1.82-2.34\%; $N=657,474)$. The estimated probit model correctly classified $98.2 \%$ of $H C H E(\operatorname{Pr}(D) \geq 0.5)$. Factors affecting the catastrophic expenditures were affiliation, presence of chronic disease, hospitalization expenditure, rural condition and that the household is below the food poverty line. Conclusions: The percentage of HCHE decreased in recent years, improving financial protection in health. This decline seems to have stalled, keeping inequities in access to health services, especially in rural population without affiliation to any health institution, below the food poverty line and suffering from chronic diseases.
\end{abstract}

KEY WORDS: Health expenditure. Out of pocket spending. Probabilistic models.

\section{Introduction}

Health System fragmentation in Mexico has favored for financing to be differentiated and through different sources for the population without and with social security. In the first case, financing comes from general taxes, whereas in the second one, from worker-employer and government contributions to social security; in both segments, there remains a component of out-of-pocket (OP) funding'. According to the Organization for Economic Cooperation and Development data, OP expenditure (OPE) in Mexico represents $45 \%$ of total health expenditure ${ }^{2}$, which paces us at first place among member countries. Owing to its nature, this funding mechanism can drive a household to incur catastrophic expenditure (CE) for reasons of health, generating high societal costs ${ }^{3}$.
A household with catastrophic health expenditure $(\mathrm{HCHE})$ is defined when it assigns $30 \%$ or more of its available income or payment capacity to health care. Available income or payment capacity has been defined by the World Health Organization (WHO) as the remnant of a household total expenditure once the basic subsistence needs are discounted, which are measured through the expenditure spent on food $\mathrm{d}^{4}$.

In Mexico, different studies have been carried out in order to determine the magnitude, the type and the number of HCHE. In 1992, the Mexican Foundation for Health/FUNSALUD - Fundación Mexicana para la Salud) indicated that in Mexico there were $2.3 \%$ of HCHE. Other studies on the subject have determined that, between the years 1992 and 2000, the percentage of $\mathrm{HCHE}$ was between 3 and $4 \%{ }^{5}$. It has been documented that households that incur $\mathrm{CE}$ to a larger extent are those found at the lowest income quintiles

\section{Correspondence:}

Román Rodríguez-Aguilar

Av. Universidad Anáhuac, 46

Col. Lomas Anáhuac

Huixquilucan

C.P. 52786, Estado de México, México

Date of reception: 19-05-2016

Date of acceptance: 19-05-2016

E-mail: roman.rodriguez@anahuac.mx

DOI://dx.doi.org/10.24875/GMM.M18000076

Gac Med Mex. 2017;153:684-691

Contents available at PubMed www.gacetamedicademexico.com 
(around $10 \%)^{6}$. In view of this problem, since the year 2001, the System for Social Protection in Health (SPSS - Sistema de Protección Social en Salud) was gradually implemented, which had among its objectives the reduction of $\mathrm{OPE}$, and especially of the percentage of $\mathrm{HCHE}$, through a financial coverage granted to the population with no access to social security?. The results observed after SPSS implementation show that CE has decreased; however, it appears to have become stagnant. In this context, the present article aims to analyze the evolution in the percentage of HCHE in Mexico for the 2002-2014 period. In addition, the main determinants for the occurrence of $C E$ are analyzed with a probit model and the main aspects of OPE and HCHE.

\section{Method}

CE on health was estimated according to the 20022014 National Survey on Household Income and Expenditure (ENIGH - Encuesta Nacional de Ingreso y Gasto de los Hogares) ${ }^{8}$. The methodology defined by the Economic Analysis Unit of the Secretary of Health (SS - Secretaría de Salud), which is based on criteria defined by the WHO in 2005 and agreed on by the National Commission for Health-related Social Protection, FUNSALUD and the General Administration for Performance Assessment of the SS, was used to determine the percentage of $\mathrm{HCHE}^{9,10}$. In addition to the $\mathrm{ENIGH}$, the items used to estimate the indicator include the definition of income and total running costs of the National Institute of Geography and Statistics, and the alimentary poverty line of the National Council for Social Policy Evaluation ${ }^{11}$ in the respective years. The formula for the HCHE calculation is the following:

$$
h g c_{i}=\left\{\begin{array}{l}
0, c f h_{i}<30 \% \\
1, c f h_{i} \geq 30 \%
\end{array}\right.
$$

Where $h c e_{i}$ are the households with CE and $h f c_{i}$ is the households' financial capacity. The financial contribution of the household to healthcare expenses is an indicator of the financial burden generated by health expenditure, which is equal to household health expenditure $\left(h h_{i}\right)$ divided by the household payment capacity $\left(h p c_{i}\right)$ defined as household effective monetary income that is above the level of subsistence.

The analysis was performed for the 2002-2014 period. In addition, a probit model was estimated to identify factors associated with higher probability of
CE occurrence. The model specification is presented in the following equation:

$$
E\left(Y_{i}=\operatorname{Prob}\left(Y_{i}=1\right)=M_{i}=\frac{e^{\alpha+\beta_{k} X_{k i}}}{1+e^{\alpha+\beta_{k} X_{k i}}}\right.
$$

where:

$$
\begin{aligned}
& M_{i}=\text { probability of the status } \\
& \qquad \begin{array}{c}
M_{i}+M_{i} e^{\alpha+\beta_{k} X_{k i}}=e^{\alpha+\beta_{k} X_{k i}} \\
M_{i}=\left(1-M_{i}\right) e^{\alpha+\beta_{k} X_{k i}} \\
\frac{M_{i}}{\left(1-M_{i}\right)}=e^{\alpha+\beta_{k} X_{k i}} \text {,odds ratio }
\end{array}
\end{aligned}
$$

Aspects concerning effective coverage related to the use of public services and household income evolution in Mexico were included in the analysis.

\section{Results}

\section{Sociodemographic}

Table 1 shows some sociodemographic and economic characteristics of the Mexican population in the 2002-2014 period. A population increase of a little more than 18.9 million people was observed in the entire period. Gender distribution has remained relatively constant over these years, with $49 \%$ of males and $51 \%$ of females. With regard to the size of settlements, $78 \%$ of households were concentrated in urban areas and $22 \%$ in rural zones. According to the National Institute of Statistical and Geographic Information (INEGI - Instituto Nacional de Información Estadística y Geográfica), urban settlements are those concentrating 2500 or more inhabitants, while rural settlements are those with less than 2500 inhabitants; this composition remained stable throughout the period.

An important increase was observed in the number of households, going from 24.6 million in 2002 to 31.7 million in 2014, which represented an increase of $28.5 \%$ (seven million households). On the other hand, the household internal structure remained relatively constant: one household member is younger than 14 years, 2.4 members are between 14 and 64 years' old, and 0.3 members are 65 years' old or older. Household average size decreased in the period from 4.1 to 3.8 members. On average, $52.6 \%$ of households reported some health expenditure in 2014.

With regard with reported affiliation, the household head affiliation was assigned to the household; this analysis could only be made since 2008 . This restriction is related to the way this is asked in the survey 


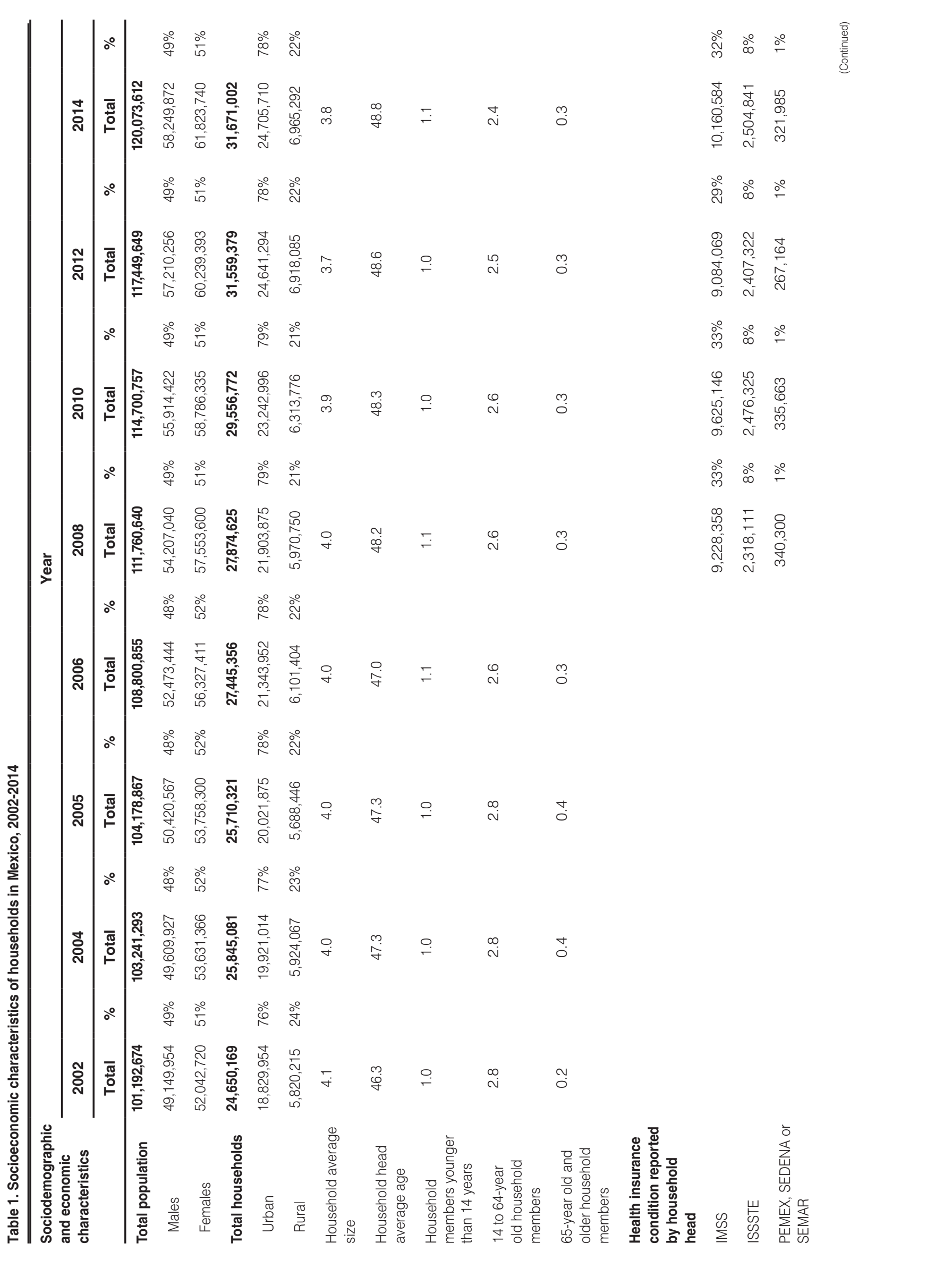




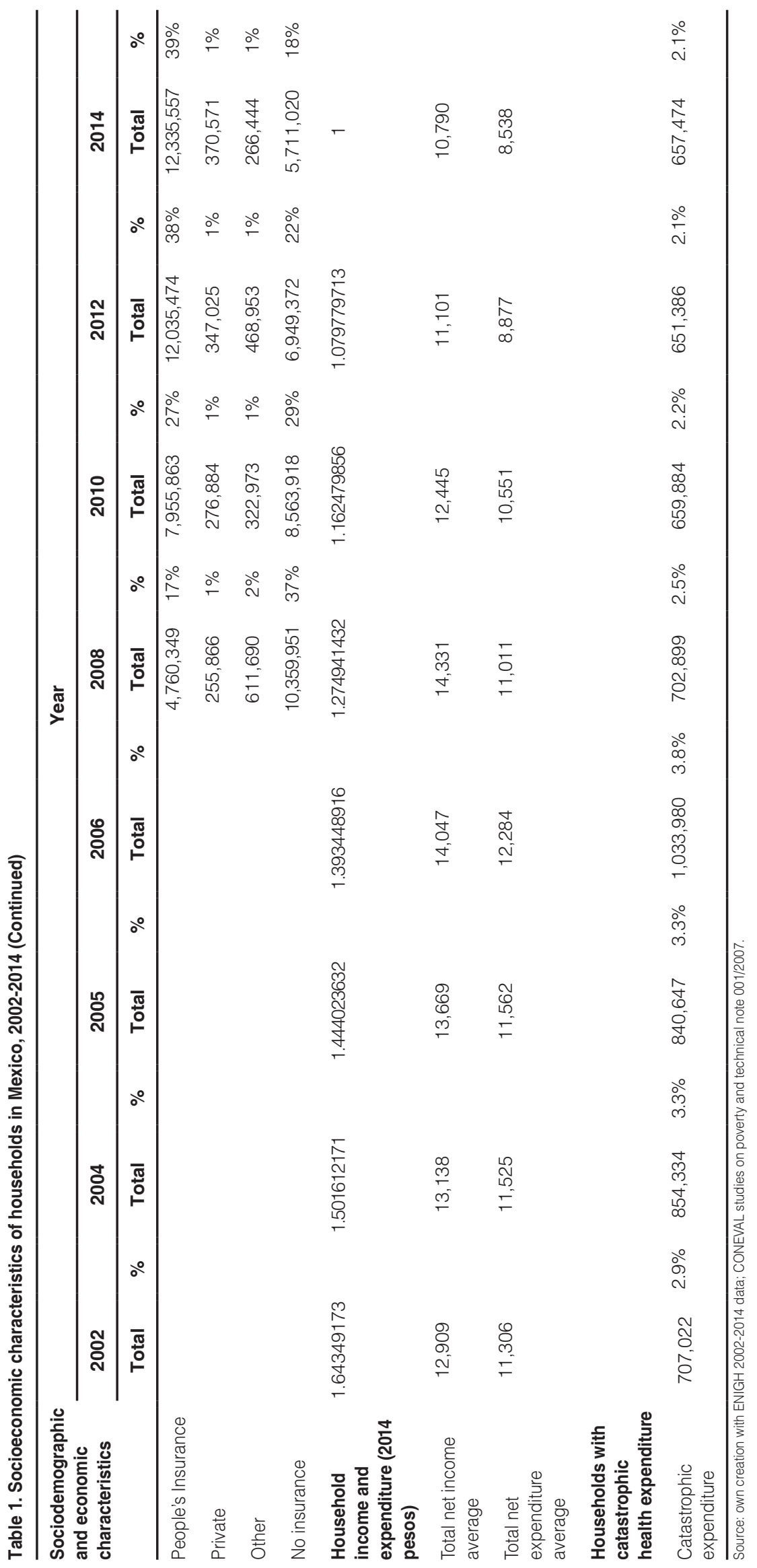


and to the fact that SPSS had not yet reached the expected levels of coverage in all states. Between 2008 and 2014, the number of households that had health insurance provided by the Mexican Institute of Social Security (IMSS - Instituto Mexicano del Seguro Social) remained relatively constant: $32 \%$ throughout the period. On the other hand, SPSS-covered households went from $17 \%$ in 2008 to $39 \%$ in 2014 . Finally, households that are not covered by any public health institution were considerably reduced as SPSS increased, going from $37 \%$ in 2008 to $18 \%$ in 2014 .

Total net household income and expenditure average evolution should be pointed out, as it showed a decreasing tendency since 2008, largely influenced by the economic cycle initiated since the 2008 world crisis. It is necessary to more deeply explore the economic cycle effect on the decrease or increase of health expenditure and, consequently, on CE, in order to be able to assess the real effect on CE decrease that is attributable to the health reforms implemented over the past few years in Mexico.

\section{Catastrophic expenditure for health reasons}

The results of the HCHE percentage estimate for the 2002-2014 are presented in figure 1. A tendency towards an increase was observed in the 2002-2006 period, which was reversed for the years 2008 through 2014. In 2012, the percentage of HCHE was estimated at $2.06 \%$, whereas for 2014 , it was estimated at $2.08 \%$. This implies that there was an increase of little more than 6000 households (equivalent to 1\%) that had health-related CE between 2012 and 2014.

The HCHE percentage reduction since 2006 is modest, and it should be considered that this reduction occurred in an adverse socioeconomic context. This is reflected in a $15.4 \%$ increase in the number of households from 2006 to 2014, as well as a reduction in household total net income average. This tendency can be linked, among other reasons, to the creation and increase in the coverage of population affiliation through the SPSS. The CE downward trend between 2008 and 2014 and coincides with the household total net income decreasing tendency, which explains the observed HCHE reduction (Fig. 2). With the information provided by ENIGH it is difficult establishing whether the CE decrease is due to public coverage increase through SPSS or to a household income decrease.

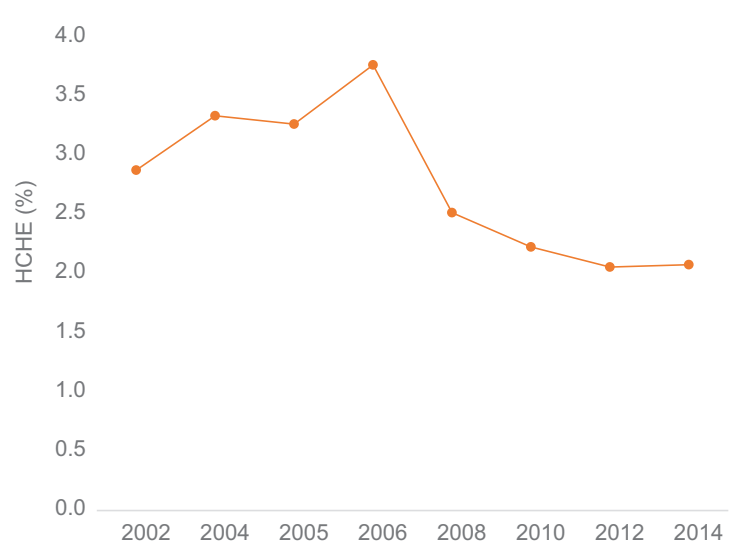

Figure 1. Households with catastrophic health expenditure (HDHE), 2002-2014. Source: own creation with ENIGH 2002-2014 data; CONEVAL studies on poverty and technical note 001/2007.
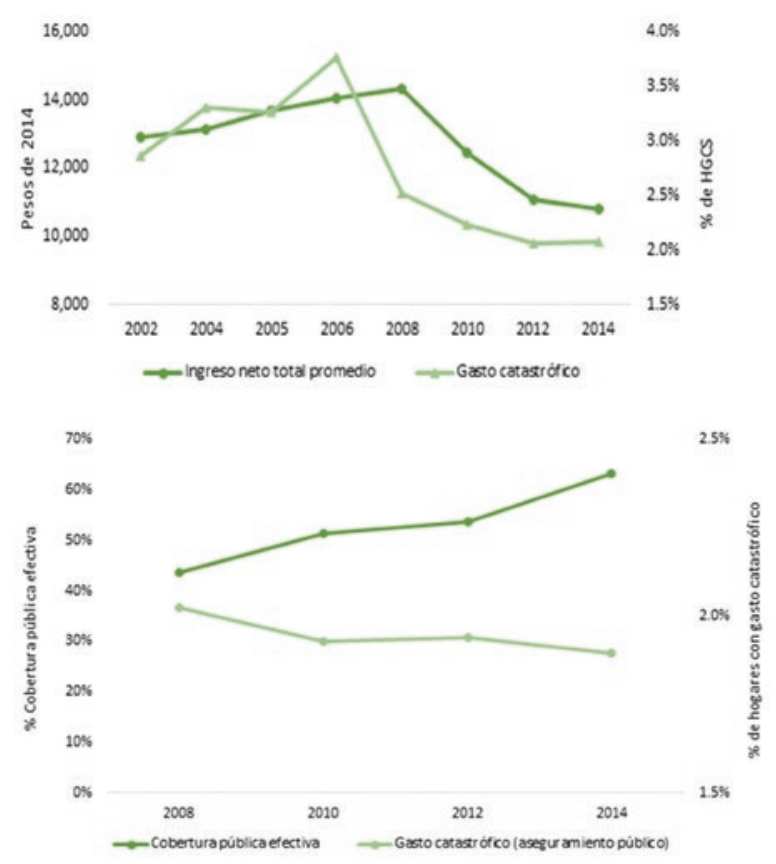

Figure 2. Total net income, effective public coverage and catastrophic health expenditure, 2002-2014. Source: own creation with ENIGH 2002-2014 data; CONEVAL studies on poverty and technical note 001/2007.

The percentage of population with public insurance that uses public healthcare services is a follow-up indicator of the 2013-2018 Health Sectoral Program (PROSESA - Programa Sectorial de Salud) ${ }^{12}$. When this indicator is associated with the percentage of $\mathrm{HCHE}$ among those households that have public insurance, the CE decrease that is attributable to public health financial protection can be indirectly evaluated. As observed in fig. 2, there is an inverse relationship between the effective coverage indicator and the $\mathrm{CE}$ indicator. 


\section{6}

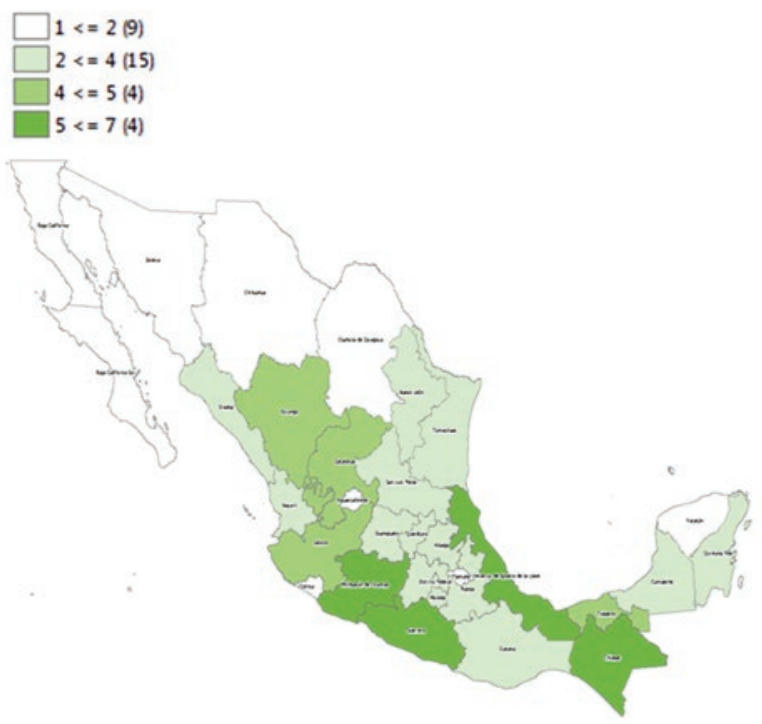

\section{4}

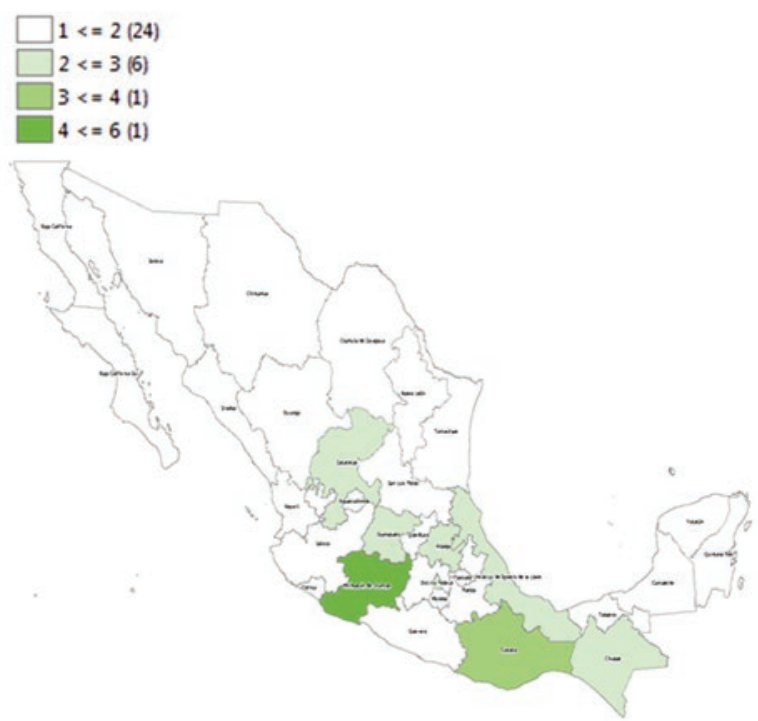

Figure 3. Households with catastrophic expenditure (CE) by State. The map presents the CE percentage the States are in $(x \leq y)$, and the number of States within said range is indicated in brackets. Source: own creation with ENIGH 2002-2014 data; CONEVAL studies on poverty and technical note 001/2007.

A direct relationship was found between household total net income and the amount assigned to health expenditure, and an inverse relationship between public insurance effective coverage and the percentage of HCHE. The decrease in the latter can be attributed to a combined effect of income decrease and public coverage increase. Public coverage increase through SPSS reduced the impact of income decrease on health-related CE.

\section{Catastrophic expenditure according to household income level, reported affiliation and rural or urban condition}

CE disaggregation considering household income level and rural or urban condition showed in 2014 that the households in the lowest income deciles had a higher incidence of CE (quintile I: $4.53 \%$; quintile II: $2.0 \%$ ). Similarly, in 2014, rural households had a higher proportion of $\mathrm{HCHE}(3.1 \%)$ than urban households $(1.8 \%)$.

Taking into consideration that CE is calculated per household, to be able to analyze the relationship between CE occurrence, income level and insurance status, each household affiliation reported by the household head was identified in ENIGH. When the $\mathrm{HCHE}$ indicator was disaggregated according to household head-reported affiliation, the percentage of $\mathrm{HCHE}$ was observed to decrease from 3.47\% in 2008 to $2.49 \%$ in those households with SPSS insurance. At the IMSS, the decrease was from 1.41 to $1.17 \%$. At the ISSSTE, there was an increase from 1.53 to $1.93 \%$, and for the population with no affiliation, there was a decrease from 3.39 to $2.76 \%$.

When the indicator was analyzed according to the income quintile and insurance status, the increases observed for first quintile households insured by the Institute of Security and Social Services of State Workers (ISSSTE - Instituto de Seguridad y Servicios Sociales de los Trabajadores del Estado) stand out since, from 2008 to 2014 , it went from $3.4 \%$ to $12.0 \%$, which implied an increase of 10,000 households with this condition. At the IMSS, for the first quintile, an increase was observed from $2.33 \%$ in 2008 to $3.30 \%$ in 2014. For households with SPSS affiliation, a decrease from $4.95 \%$ in 2008 to $3.82 \%$ in 2014 was observed in the first quintile. Finally, households with no affiliation reported had an increase from 5.46 to $6.73 \%$ in the first income quintile.

\section{Catastrophic expense by State}

Although ENIGH is not representative by State, the percentage of HCHE is informatively presented comparing the years 2006 and 2014, prior and after SPSS national implementation (Fig. 3). In 2006, 8 States had a $\mathrm{HCHE}$ percentage in the range from 4 to $7 \%, 15$ in a range from 2 to $4 \%$, and nine between 1 and $2 \%$. 
Gaceta Médica de México. 2017;153

Table 2. Catastrophic expenditure probit model: marginal effects

\begin{tabular}{|c|c|c|c|c|c|c|}
\hline \multirow{2}{*}{$\frac{\text { Variable }}{\text { Affiliation* }}$} & \multirow{2}{*}{$\frac{\mathrm{dy} / \mathrm{dx}}{-0.0058381}$} & \multirow{2}{*}{$\frac{\text { SE }}{0.00254}$} & \multirow{2}{*}{$\frac{\mathbf{z}}{-2.29}$} & \multirow{2}{*}{$\frac{\mathbf{P}>\mathbf{z}}{0.022}$} & \multicolumn{2}{|c|}{$95 \% \mathrm{Cl}$} \\
\hline & & & & & -0.010826 & -0.000851 \\
\hline Chronic* & 0.0800964 & 0.01349 & 5.94 & 0.000 & 0.053649 & 0.106544 \\
\hline Hospitalization* & 0.0000274 & 0.00000 & 8.92 & 0.000 & 0.000021 & 0.000033 \\
\hline Rural/urban condition* & 0.0090252 & 0.00224 & 4.04 & 0.000 & 0.004643 & 0.013407 \\
\hline Food poverty line* & 0.0076359 & 0.00398 & 1.92 & 0.045 & -0.000156 & 0.015428 \\
\hline
\end{tabular}

*Significant at 95\% confidence.

Number of observations: 19,479; Wald $\chi^{2}$ (5) 268.60; Prob > $\chi^{2}$ (0.0000); Log likelihood: 1367.0439; probability of marginal effects: $98.19 \%$.

Source: own creation with ENIGH 2002-2014 data; CONEVAL studies on poverty and technical note 001/2007.

By 2014, the panorama had significantly changed: 24 States were in a range from 1 to $2 \%$, six, between 2 and $3 \%$, one between 3 and $4 \%$, and one between 4 and $6 \%$ (Fig. 3). The States with the highest percentage of $\mathrm{HCHE}$ in 2014 were Guanajuato (3.9\%), Oaxaca (3.5\%) and Michoacán (5.8\%), whereas the States with the lowest percentages were Nuevo León $(0.71 \%)$, Sonora $(0.73 \%)$ and the State of Mexico $(0.75 \%)$. From 2006 to 2014, 27 States had an average decrease of $48 \%$ in the indicator and 5 had an average increase of $46 \%$.

\section{Factors associated with the occurrence of catastrophic expenditure}

A probit model was estimated to determine factors influencing on the probability for a household to incur CE. The binary dependent variable probabilistic model considered all household characteristics available in ENIGH. However, by means of the validation process, the final model contemplated household affiliation and whether the household has members with chronic diseases (this indicator was identified through the expenditure on diabetes and hypertension-related medications) as significant variables; hospitalization expenses and rural or urban condition of the household were also considered. Finally, the income level was contemplated by estimating the poverty lines defined by SEDESOL: food, capabilities and patrimonial poverty (Table 2 ).

The estimated probit model was significant and efficient when classifying HCHEs based on the model with $\operatorname{Pr}(\mathrm{D}) \geq 0.5$ ); $98.19 \%$ of cases were correctly classified. Determinants for a household to incur CE were affiliation, households with members with chronic diseases, households with hospitalization expenses, rural condition and the fact of the household being below the food poverty line. The coefficient signs show that affiliation is a protecting factor to disincentivize CE; having any affiliation decreases the probability to incur CE. On the other hand, households with members who suffer from chronic conditions are more likely to incur CE, as well as those with hospital expenses. The rural condition positively influenced on the probability of CE occurrence. Finally, as regards poverty lines, food poverty was significant, which makes it a clear determinant in the occurrence of CE.

Marginal effects showed that affiliation to any health institution decreases the likelihood to incur CE by $0.5 \%$, that the presence of individuals with chronic conditions increases by $8 \%$ the probability of $\mathrm{CE}$, that the rural condition increases it by $0.9 \%$, being below the food poverty line by $0.7 \%$, and spending on hospitalization positively contributes with $0.002 \%$. Although hospital expenditure has an effect on the likelihood of CE occurrence, this effect is marginal (hospitalization expenditure not necessarily implies $\mathrm{CE}$, which can be explained because, in general, hospitalization expenditure was for delivery care).

Disaggregation of the model by institution of affiliation shows that those households that reported being affiliated to the IMSS or to private insurance companies, and those who have no affiliation at all, were the households with higher probabilities to incur CE. In the case of the households with capabilities and patrimonial poverty, the results were not statistically significant. On the other hand, the OPE analysis by component in 2014 indicates that expenditure on medications represents the highest proportion $(61.3 \%$ : $33.4 \%$ prescription medications and $27.9 \%$ OTC medications), followed by outpatient visits $(25.2 \%)$, other (7.9\%), pregnancy and delivery (4.1\%) and hospitalization (2.1\%). This trend in expenditure concentration in medications is maintained when analyzing the public health insurance status and the type of expenditure made. However, it should be mentioned that, for the SPSS, IMSS and ISSSTE, the proportion spent on 
prescription medications in 2014 decreased with regard to 2006.

\section{Discussion}

The results of the analysis of the HCHE percentage in Mexico indicate that there is a relationship with the household income, effective coverage of public institutions, insurance status, size of locality and the area of health expenditure. The fact stands out that, even with public health coverage expansion in 2014, 52.6\% of households reported OPE on health and, $2.08 \%, \mathrm{CE}$.

From the results it is possible to identify that living in a rural area significantly influences on households incurring $\mathrm{CE}$. The analysis by insurance status suggests that the financial protection deficit continues to be present, regardless of the public insurance status. However, assessing the effect of health demand substitution is necessary, since it is probable that, when increasing public coverage, households dedicate a percentage of their income to health areas not covered by public insurance plans. It should be pointed out that a household covered by the SPSS at the first and last income quintile has a higher probability to incur health-related CE. However, it is necessary to recognize that SPSS-covered households showed a significant reduction in CE between 2008 and 2014. For the first income quintile, HCHEs show a downward trend, which is consistent with the goals established in 2013-2018 PROSESA. These results offer a guideline to consider that, although public health insurance expansion contributes to the reduction in the number of households in health expenditure extreme situations, it is not sufficient to influence on a health-related CE absolute decrease. Consequently, it is necessary for the effect of the income decrease and public health insurance effective coverage increase to be assessed as possible causes of the reduction of the $\mathrm{HCHE}$ percentage in Mexico.
In most States, there was a HCHE percentage decrease between 2006 and 2014. Even when there have been important advances, the challenge remains of reducing the $\mathrm{HCHE}$ percentage in those States that had had percentages ranging from 3 to up to $6 \%$. Additionally, the presence of chronic conditions represents an important financial burden that increases the likelihood to incur CE.

The role of CE in the Mexican National Health System indicates the persistence of inequities in both financing and access to health services, particularly to medications. These inequities should be analyzed in an inter-sectoral context.

\section{References}

1. Comisión Mexicana sobre Macroeconomía y Salud. Macroeconomía y salud: invertir en salud para el desarrollo económico. México: Fondo de Cultura Económica, Secretaría de Salud, Fundación Mexicana para la Salud, Instituto Nacional de Salud Pública, Secretaría de Hacienda y Crédito Público, Comisión Mexicana sobre Macroeconomía y Salud; 2006.

2. OECD (2013), Health at a Glance 2013: OECD Indicators, OECD Publishing. Disponible en: http://dx.doi.org/10.1787/health_glance-2013-en

3. Kelly MP, Morgan A, Bonnefoy J, et al. The social determinants of health: developing an evidence base for political action. Universidad del Desarrollo, Chile, and National Institute for Health and Clinical Excellence, United Kingdom; 2007 (Final Report to Commission on the Social Determinants of Health of the World Health Organization).

4. Organización Mundial de la Salud. Subsanar las desigualdades en una generación: alcanzar la equidad sanitaria actuando sobre los determinantes sociales de la salud. Informe final de la Comisión sobre los Determinantes Sociales de la Salud. Geneva: OMS; 2009.

5. Knaul F, Arreola H, Méndez O. Protección financiera y gasto catastrófico de los hogares en Caleidoscopio de la Salud. México D.F.: Funsalud; 2003.

6. Knaul FM, Arreola $\mathrm{H}$, Méndez $\mathrm{O}$, et al. Las evidencias benefician al sistema de salud: reforma para remediar el gasto catastrófico y empobrecedor en salud en México. Salud Publica México. 2007; 49(Supl 1):S70-S87.

7. González E, Barraza M, Gutiérrez C, et al. Sistema de Protección Social en Salud: elementos conceptuales, financieros y operativos. México: Fondo de Cultura Económica, Secretaría de Salud, Fundación Mexicana para la Salud, Instituto Nacional de Salud Pública; 2006.

8. Instituto Nacional de Estadística y Geografía - INEGI. Encuesta Nacional de Ingreso y Gasto de los Hogares 2002-2014. ENIGH, 2002-2014. México, 2015.

9. Secretaría de Salud. Rendición de Cuentas en Salud 2008-2012. Dirección General de Evaluación del Desempeño, Subsecretaría de Integración y Desarrollo del Sector Salud. México, 2013.

10. Unidad de Análisis Económico. Metodología para la estimación del gasto catastrófico y empobrecedor en salud de los hogares mexicanos. México: Secretaría de Salud; 2009.

11. CONEVAL. Medición de la pobreza en México: metodología para la medición de la pobreza por ingresos. 2002-2014 CONEVAL. México; 2015.

12. Secretaría de Salud. Programa Sectorial de Salud 2013-2018. México; 2013. 